\title{
Postnatal Evaluation and Outcome of Prenatal Hydronephrosis
}

\author{
Simin Sadeghi-Bojd, ${ }^{1, *}$ Abdol-Mohammad Kajbafzadeh, ${ }^{2}$ Alireza Ansari-Moghadam, ${ }^{3}$ and \\ Somaye Rashidi ${ }^{1}$ \\ ${ }_{2}^{1}$ Research Center for Children and Adolescents, Zahedan University of Medical Sciences, Zahedan, IR Iran \\ ${ }_{3}^{2}$ Department of Urology, Pediatric Urology Research Center, Children's Medical Center, Tehran University of Medical Sciences,Tehran, IR Iran \\ ${ }^{3}$ Health Promotion Research Center, Zahedan University of Medical Sciences, Zahedan, IR Iran \\ ${ }^{*}$ Corresponding author: Simin Sadeghi-Bojd, Research Center for Children and Adolescents, Zahedan University of Medical Sciences, Zahedan, IR Iran. Tel: +98-5412440482, Fax: \\ +98-5413425596, E-mail: sisadegh@yahoo.com
}

Received 2015 July 27; Revised 2015 November 22; Accepted 2015 December 19.

\begin{abstract}
Background: Prenatal hydronephrosis (PNH) is dilation in urinary collecting system and is the most frequent neonatal urinary tract abnormality with an incidence of $1 \%$ to $5 \%$ of all pregnancies. PNH is defined as anteroposterior diameter (APD) of renal pelvis $\geq 4 \mathrm{~mm}$ at gestational age (GA) of $<33$ weeks and APD $\geq 7 \mathrm{~mm}$ at GA of $\geq 33$ weeks to 2 months after birth. All patients need to be evaluated after birth by postnatal renal ultrasonography (US). In the vast majority of cases, watchful waiting is the only thing to do; others need medical or surgical therapy.

Objectives: There is a direct relationship between APD of renal pelvis and outcome of PNH. Therefore we were to find the best cutoff point APD of renal pelvis which leads to surgical outcome.

Patients and Methods: In this retrospective cohort study we followed 200 patients 1 to 60 days old with diagnosis of PNH based on before or after birth ultrasonography; as a prenatal or postnatal detected, respectively. These patients were referred to the nephrology clinic in Zahedan Iran during 2011 to 2013. The first step of investigation was a postnatal renal US, by the same expert radiologist and classifying the patients into 3 groups; normal, mild/moderate and severe. The second step was to perform voiding cystourethrogram (VCUG) for mild/ moderate to severe cases at 4 - 6 weeks of life. Tc-diethylene triamine-pentaacetic acid (DTPA) was the last step and for those with normal VCUG who did not show improvement in follow-up examination, US to evaluate obstruction and renal function. Finally all patients with mild/moderate to severe PNH received conservative therapy and surgery was preserved only for progressive cases, obstruction or renal function $\leq 35 \%$. All patients' data and radiologic information was recorded in separate data forms, and then analyzed by SPSS (version 22 ). Results: 200 screened PNH patients with male to female ratio 3.5:1 underwent first postnatal control US, of whom $65 \%$ had normal, $18 \%$ mild/moderate and $17 \%$ severe hydronephrosis. 167 patients had VCUG of whom $20.82 \%$ with VUR. 112 patients performed DTPA with following results: 50 patients had obstruction and 62 patients showed no obstructive finding. Finally $54 \%$ of 200 patients recovered by conservative therapy, $12.5 \%$ by surgery and remaining improved without any surgical intervention.

Conclusions: The best cutoff point of anteroposterior renal pelvis diameter that led to surgery was $15 \mathrm{~mm}$, with sensitivity $88 \%$ and specificity $74 \%$.
\end{abstract}

Keywords: Prenatal Hydronephrosis, Renal Pelvis, Ultrasonography

\section{Background}

Prenatal hydronephrosis (PNH) is the most common cause of kidney and urinary tract abnormality in perinatal period by a prevalence of $1 \%$ to $5 \%$ of pregnancies (1-4). Diagnosis of PNH is based on renal ultrasonography (US) before and/or after birth. In fetal US, PNH is defined as anteroposterior renal pelvis diameter (APD) $\geq 4 \mathrm{~mm}$ at gestational age less than 33 weeks and APD $\geq 7 \mathrm{~mm}$ at gestational age $\geq 33$ weeks. After birth the presence of persistent urinary tract dilation seems to be the most important landmark and APD $>10 \mathrm{~mm}$ is abnormal (5-7).

PNH may occur by many conditions that affect kid-

Copyright @ (2016, Growth \& Development Research Center. This is an open-access article distributed under the terms of the Creative Commons Attribution-NonCommercial 4.0 International License (http://creativecommons.org/licenses/by-nc/4.0/) which permits copy and redistribute the material just in noncommercial usages, provided the original work is properly cited. 
ney and urinary collecting system. Its main underlying etiologies include: transient or physiologic hydronephrosis, ureteropelvic junction obstruction (UPJO), vesicoureteral reflux (VUR), dilated ureter, multicystic dysplastic kidney, duplicated ureter. The most common cause of prenatal hydronephrosis is transient; a physiologic condition accounting for approximately $60 \%$ of cases $(2,7-9)$.

The intensity and severity of PNH is classified to nor$\mathrm{mal}($ APD $\leq 9.9 \mathrm{~mm})$, $\mathrm{mild} /$ moderate $(10 \mathrm{~mm} \leq \mathrm{APD} \leq$ $14.9 \mathrm{~mm}$ ) and severe (APD $\geq 15 \mathrm{~mm}$ ) according to APD of renal pelvis in US, based on society for fetal urology guidelines $(2,10-12)$. This grading system enables us to detect patients with serious pathology and complications or need for surgery, on the other hand, it shows the mild cases who do not need any surgical intervention and might have favorable prognosis (13-17). Outcome of PNH also relates to underlying etiology; for example, the best outcome have those with transient UPJO and dilated ureter.

Most involved infants are asymptomatic, that shows the importance of prenatal diagnosis by at least one prenatal ultrasonography. Therefore many patients recover without any surgical intervention. When symptoms arise, the finding does not improve, it may be incurable or difficult to treat (8). Type of intervention and final prognosis can be predicted based on the diameter of renal pelvis $(9,18)$.

\section{Objectives}

We conducted a retrospective study to determine the correlation between the anteroposterior diameter of renal pelvis in postnatal ultrasonography and the probability of surgical intervention.

\section{Patients and Methods}

In this retrospective cohort study, infants with diagnosis PNH referred to nephrology clinic during 2011 and 2013 in Zahedan, Iran, were enrolled. PNH was defined as renal pelvis APD in ultrasonography $\geq 4 \mathrm{~mm}$ at gestational age (GA) $>33$ weeks, and APD $\geq 7 \mathrm{~mm}$ at GA $\geq 33$ weeks and after birth up to 2 months of age $(2,10,19,20)$. All patients with diagnosis PNH underwent at least one postnatal renal US in the first week of life by the same expert radiologist to collect comparable data without bias (21). In infants with normal 1st US, the 2nd ultrasonography was performed at 4 weeks after birth (22). Based on 1st postnatal ultrasonography our patients were classified into 3 groups; normal (APD $\leq 9.9 \mathrm{~mm}$ ), mild/moderate $(10 \mathrm{~mm} \leq$ APD $\leq 14.9 \mathrm{~mm})$ and severe(APD $\geq 15 \mathrm{~mm}$ ) hydronephrosis. Most patients with mild PNH (APD $\leq$ $9.9 \mathrm{~mm}$ ) had neither serious underlying pathology nor decreased renal function $(15,23)$, but it was necessary to re-examin them when 4 weeks old by another US. If there was no hydronephrosis, no further follow up was needed, but if hydronephrosis was presented VCUG was recommended. On the other hand, patients of severe group (APD $\geq 15 \mathrm{~mm}$ ) had high risk of postnatal pathology and required close follow-up (10). The second step to follow-up these patients was voiding cystourethrogram (VCUG). Patients with documented vesicoureteral reflux (VUR) received prophylactic antibiotics due to increased risk of urinary tract infection (UTI) (24) and DMSA was the next modality to evaluate the renal parenchyma. Some patients with normal VCUG, who had improved in follow up and fourth week sonography, were directly put on conservation therapy with no other diagnosis modeling.

The third step was Tc-diethylene triamine-pentaacetic acid (DTPA) after 6 - 8 weeks of life in patients with normal VCUG in whom hydronephrosis was still present in follow up sonography. This modality shows obstruction in urinary tract system by delaying in kidneys spontaneous drainage. PNH with normal DTPA is considered as dilated ureter. Differential renal function $45 \%$ to $55 \%$ is normal and below $35 \%$ is significantly impaired (25-27). Other clues for obstruction is unilateral renal function $\geq$ $55 \%$ and prolonged drainage of $50 \%$ of radionuclide $>20$ minutes (28-30). Partial obstruction was known as drainage only after IV furosemide.

All patients with mild/moderate to severe PNH received conservative management and surgery was preserved for $(7,10)$ :

-Those with no response to conservative therapy or with posterior urethral valves (PUV) immediately.

- Any type of obstruction with renal function $\leq 35 \%$.

- Worsening in renal function or dilation in patients with bilateral hydronephrosis or hydronephrosis in single kidney.

Other indications for surgery include pain, palpable renal mass and recurrent pyelonephritis (31).

For normal collecting system in the first control US and patients with mild hydronephrosis, second US was performed at 4 weeks of life and if no hydronephrosis existed, no further follow up was needed. If hydronephrosis was present, the next step was VCUG.

Patients were followed every 3 months during first year and every 6 months in the second year.

This study was confirmed by ethic's committee of Zahedan University of Medical Sciences (ethic No. 91-714) and in all stages of this study, we were loyal to Helsinki declaration principles. Written consent was obtained from all of participants/parents and they were free to exit the study by their will.

Data were extracted from information forms and described in Tables 1 - 5. All data was analyzed by SPSS software (version 22). Methods have been identified in Figure 1. 


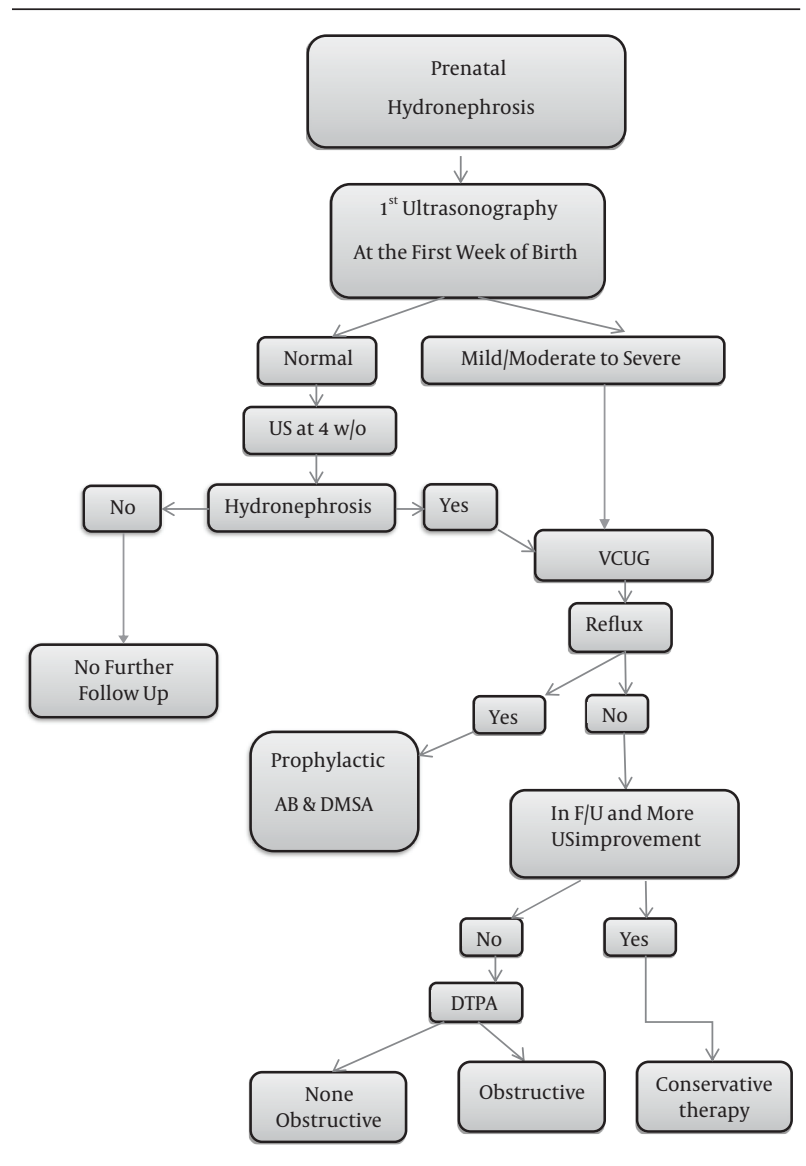

Figure 1. Clinical Approach to $\mathrm{PNH}$

\section{Results}

Patients presented to this study were 200 with mean age of 23.85 (range 1 to 60) days at arrival, and 78\% were boys (boys to girls ratio 3.5:1). In the first postnatal US, 93\% had hydronephrosis equal to 223 renal units (149 unilateral and 37 bilateral) with a mean APD of renal pelvis of $10.47 \mathrm{~mm}$ and standard deviation of $6.81 \mathrm{~mm}$ (range 3 to $44 \mathrm{~mm})$.

In the first postnatal ultrasonography patients were classified into normal (65\%), mild/moderate (18\%) and severely (17\%) affected groups.

The second ultrasonography was performed at 1 month after birth for 130 infants in whom first ultrasonography after birth was normal. The result of which was as follows: 33 infants were still normal, 99 infants showed hydronephrosis to some extent, they were conducted to the next step, namely VCUG.

VCUG was performed in 167 (83.5\%) patients, equal to 57 (13 unilateral and 22 bilateral) refluxing renal units, and VUR was detected in 35 (20.83\%) patients. VUR incidence in males was $68.57 \%$ and in females $31.43 \%$. For this group of patients with positive VUR prophylactic antibiotics for UTI were started.

112 patients required to be evaluated by DTPA, 50 (25\%)
Table 1. Demographic and Radiologic Characteristics and Prognosis of the Patients

\begin{tabular}{|cc}
\hline Parameter & No. $(\%)$ \\
\hline Total & $200(100)$ \\
\hline Gender & $156(78)$ \\
\hline Male & $44(22)$ \\
\hline Female & 200 \\
\hline First control postnatal renal US & $130(65)$ \\
\hline Normal & $36(18)$ \\
\hline Mild/Moderate & $34(17)$ \\
\hline Severe & 167 \\
\hline VCUG & $132(66)$ \\
\hline Normal & $35(20.82)$ \\
\hline Reflux & $13(6.5)$ \\
\hline Unilateral & $22(11)$ \\
\hline Bilateral & 112 \\
\hline DTPA & $62(31)$ \\
\hline Non-obstructive & $50(25)$ \\
\hline Obstructive & $35(17.5)$ \\
\hline Partial Obstruction & $15(7.5)$ \\
\hline Complete Obstruction & 200 \\
\hline Prognosis & $67(33.5)$ \\
\hline Spontaneous Recovery & $108(54)$ \\
\hline Conservative Therapy & $25(12.5)$ \\
\hline Surgery & \\
\hline
\end{tabular}

patients had 35 (17.5\%) partial obstruction and 15 (7.5\%) complete obstruction and 62 (46.43\%) patients presented no obstruction; 15 patients had decreased renal function, 10 patients had non-functional kidney due to severe hydronephrosis or MCDK and 37 patients had normal kidney.

The most common (28\%) cause of hydronephrosis was transient UPJO, the second cause was UPJO (18\%) with unilateral to bilateral ratio 8 . The third cause was VUR in 30 (15\%) patients. The other causes consisted of dilated ureter (8.5\%), neurogenic bladder (2.5\%), duplicated ureter (2\%), multicystic dysplastic kidney (1.5\%), neurogenic bladder + renal agenesis, the same as ureterocele ( $1 \%$ ) and duplicated ureter associated with UPJO or renal agenesis + UPJO (0.5\%). Duration of follow-up was variable from one month to 3 years, in average about one year. During this period, 67 (33.5\%) patients had spontaneous recovery (Based on ultrasonography or VCUG) and the remaining patients received conservative therapy of whom $25(12 \%)$ patients did not respond to medical therapy so underwent surgery; 7 (28\%) patients were female and 18 patients (72\%) male. The most underlying etiology resulting in surgery was UPJO (36\%) and UVJO (16\%). Statistical analysis (numbers and percentages) of patients is indicated in Tables $1-5$ and Figure 2. 
Sadeghi-Bojd S et al.

\begin{tabular}{lcc}
\hline Table 2. Underlying Cases of PNH & & \\
\hline Etiology & Total & Surgery \\
\hline Normal & $33(16.5)$ & 0 \\
Transient UPJO & $56(28)$ & 0 \\
UPJO & $36(18)$ & $9(4.5)$ \\
UVJO & $5(2.5)$ & $4(2)$ \\
VUR & $30(15)$ & $5(2.5)$ \\
Multicystic Dysplastic & $3(1.5)$ & 0 \\
Others $^{\text {b }}$ & $37(18.5)$ & $7(3.5)$ \\
\hline
\end{tabular}

${ }^{\mathrm{a}}$ Values are expressed as No. (\%).

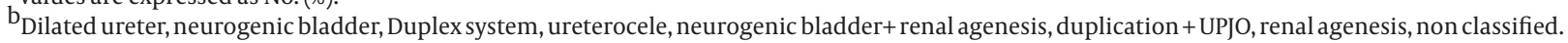

\begin{tabular}{lccc}
\hline Table 3. Surgical Outcome in Patients With VUR & & & \\
\hline Parameter & \multicolumn{2}{c}{ Gender } & Total \\
\cline { 2 - 4 } & Male & Female & $30(15)$ \\
\hline VUR & $20(10)$ & $10(0.5)$ & $3(1.5)$ \\
VUR + UPJO & $2(1)$ & $1(0.05)$ & $1(0.5)$ \\
VUR + Renal agenesis & $1(0.5)$ & 0 & $1(0.5)$ \\
VUR + Multicystic & $1(0.5)$ & 0 & \\
\hline
\end{tabular}

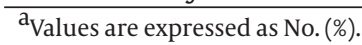

\begin{tabular}{|c|c|c|c|c|c|}
\hline \multirow[t]{2}{*}{ VCUG } & \multicolumn{3}{|c|}{ Gender } & & \multirow[t]{2}{*}{ Total } \\
\hline & \multicolumn{2}{|c|}{ Male } & \multicolumn{2}{|l|}{ Female } & \\
\hline Unilateral & \multicolumn{2}{|c|}{$7(3.5)$} & $6(3)$ & & $13(6.5)$ \\
\hline Bilateral & \multicolumn{2}{|c|}{$17(8.5)$} & \multicolumn{2}{|l|}{$5(2.5)$} & $22(11)$ \\
\hline \multicolumn{6}{|l|}{${ }^{a}$ Values are expressed as No. (\%). } \\
\hline \multicolumn{6}{|c|}{ Table 5. PNH Grading Based on Gender and Surgical Outcome ${ }^{\mathrm{a}}$} \\
\hline \multirow[t]{2}{*}{ Grad of Hydronephrosis } & \multicolumn{2}{|c|}{ Gender } & \multirow[t]{2}{*}{ Total } & \multirow[t]{2}{*}{ Surgery } & \multirow[t]{2}{*}{ P Value } \\
\hline & Male & Female & & & \\
\hline Normal & $102(51.5)$ & $28(14)$ & $130(65)$ & $3(1)$ & 0.00 \\
\hline Mild/Moderate & $27(13.5)$ & $9(4.5)$ & $36(18)$ & $10(5)$ & 0.00 \\
\hline Severe & $27(13.5)$ & $7(3.5)$ & $34(17)$ & $12(6)$ & 0.00 \\
\hline
\end{tabular}

${ }^{\mathrm{a}}$ Normal: $\leq 9.9 \mathrm{~mm}$; mild/moderate: $10-14.9 \mathrm{~mm}$; severe: $\geq 15 \mathrm{~mm}$.

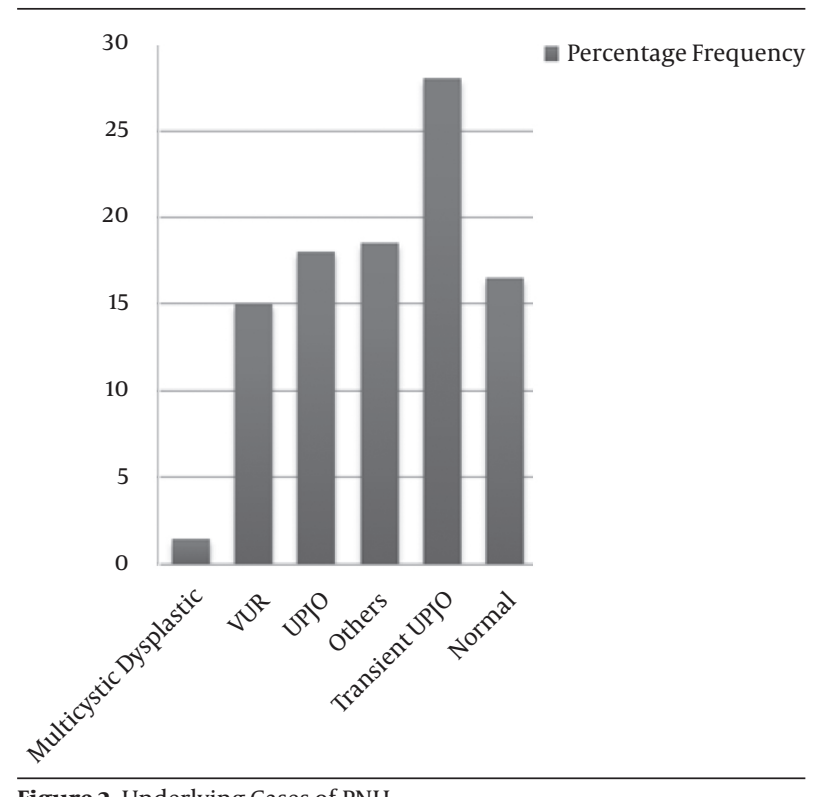

Figure 2. Underlying Cases of PNH

\section{Discussion}

With the widespread use of US in pregnancies the recognition of prenatal hydronephrosis has increased (2, 5, $10,18,32,33)$. We use US to evaluate PNH. In some papers it has been emphasized that US is the best and powerful tool that is the first examination to be performed after birth $(5,34)$. VCUG may be safely reserved for high grade PNH (35).

In this investigation at first we used US for all patients, then VCUG and DTPA if indicated. Payabvash et al. introduced MRU to evaluate patients with congenital urogenital anomalies when other modalities are within equivocal results (36).

Boys to girls ratio 3.5:1 shows the dominance of mail in urinary tract abnormalities which is similar to the study by Bassanese et al. (Male to female ratio 7:1) (37).

Lee et al. in a study 2014 showed that out of 262 patients with PNH $18 \%$ had VUR which was the same as in our study (15\%) (38).

Tombesi and Alconcher in 2012 evaluated 193 prenatal 
hydronephrotic newborns with APD $<15 \mathrm{~mm}$ and concluded that $73 \%$ of renal units resolved after one year follow up, in present study $72 \%$ of patients with APD $<15 \mathrm{~mm}$ recovered spontaneously or by conservative management (17). Hydronephrosis based on first US was in 149 (74.5\%) cases unilateral and 37 (18.5\%) bilateral.

Anthony Herndon et al. in 1999 found that approximately 10 to $30 \%$ of cases with prenatal hydronephrosis presented with postnatal diagnosis of VUR, the majority of whom were boys with higher grades and more bilateral, completely the same as in this study (20.83\% VUR, $68.57 \%$ in males) (39). In a paper written by Ismaili et al. $33 \%$ of neonatal hydronephrotic patients had abnormal VCUG (19).

Nguyen et al. (22) in the society for fetal urology consensus statement revealed that underlying etiologies of PNH included transient hydronephrosis ( $41 \%$ - 88\%), UPJO (10\% - 30\%), VUJO (5\% - 10\%) and VUR (10\% - 20\%), etc, which are similar to the results found by Lee et al. in 2006 (40) and our study.

During follow up, 25 patients of our cases needed surgery. Finding the cutoff point of APD in patients with PNH could lead to better follow-up and treatment, also it could prevent from unnecessary follow up. Several studies on PNH were done in different countries to obtain the best prediction of prognosis. These studies are designed to determine the best cutoff point of diameter of the renal pelvis leading to a surgical procedure. Similar studies have been done in the direction on fetuses and infants. Sharifian et al. in 2014 followed 178 neonates in Iran and showed that $42(23 \%)$ patients needed surgery. In this study the best APD cutoff to predict surgery was $15 \mathrm{~mm}$, the same as in our study (2).

Policiano et al. in 2014 by ultrasonography before birth showed that the APD $10 \mathrm{~mm}$ is strongly associated with surgery (41). In 2014, Vemulakonda et al. reported that all fetuses with any gestational age and renal pelvis diameter greater than or equal to $10 \mathrm{~mm}$ are known as severe PNH and need careful follow-up (18). In the article written by Safai Asl and Maleknejad the authors showed that cutoff point of APD is $10 \mathrm{~mm}$ in 20 weeks gestational age, $12 \mathrm{~mm}$ in 30 weeks gestational age, and $15 \mathrm{~mm}$ postnatal had most communication with the next pyeloplasty (42). Study on 178 PNHs showed that specific cutoff point 15 $\mathrm{mm}$ indicates the surgical pyeloplasty (2). Tombesi and Alconcher considered mild PNH and concluded only 1.5\% of patients required surgery treatment (17). In the same paper, these percentages are respectively $70 \%$ and $2.4 \%$ (43). The authors, in the paper entitled "Incidence and outcomes of antenatally detected congenital hydronephrosis" reported that the best predictor, for incurable PNH and the possibility of underlying pathology (such as anatomic abnormalities) in postnatal anteroposterior diameter equal to $5 \mathrm{~mm}$ had a sensitivity of $83 \%$, equal to $7 \mathrm{~mm}$ had a sensitivity of $88 \%$ and $10 \mathrm{~mm}$ had a sensitivity of $94 \%(20)$.

Mudrik-Zohar et al. in an article stated that APD $>14 \mathrm{~mm}$ is the best cutoff point for surgery with sensitivity of $77 \%$ and specificity of $69 \%$, using the ROC curve 0.817 (44).

In the present study, $200 \mathrm{PNH}$ cases were enrolled, the best APD leading to surgical treatment was $15 \mathrm{~mm}$ with the sensitivity of $88 \%$ and specificity of $74 \%$ (Figure 3 ).

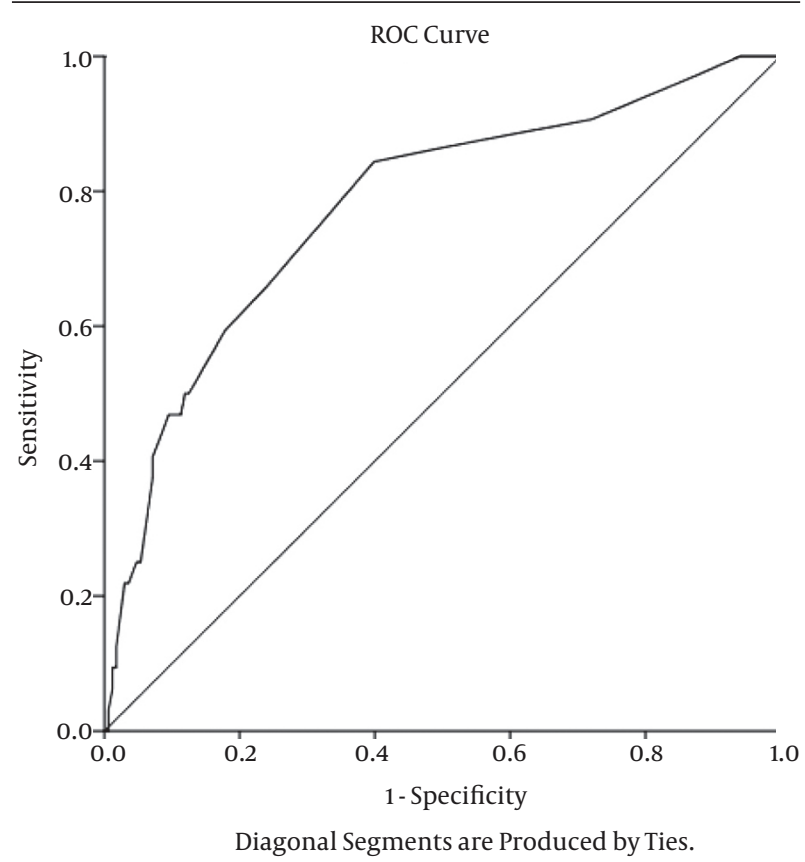

Figure 3. Sensitivity and Specificity of Cutoff Point of Renal Pelvis APD Leading to Surgical Intervention

\subsection{Conclusions}

As PNH is an asymptomatic disease in early stages of life and its screening with US is very important, we showed an APD cutoff about $15 \mathrm{~mm}$ in the first week after birth in US is the most leading issue to a surgical outcome, thus less than that point means to have a successful conservative therapy.

\section{Acknowledgments}

The authors thank all colleagues in pediatrics ward and research center for children and adolescents health and laboratories for their help in preparing data.

\section{Footnote}

Funding/Support:This study was supported by Zahedan University of Medical Sciences, Zahedan, Iran.

\section{References}

1. Godinho AB, Nunes C, Janeiro M, Carvalho R, Melo MA, da Graca LM. Ureterocele: antenatal diagnosis and management. Fetal Diagn Ther. 2013;34(3):188-91. doi: 10.1159/000353388. [PubMed: 23969704]

2. Sharifian M, Esfandiar N, Mohkam M, Dalirani R, Baban Taher E, Akhlaghi A. Diagnostic accuracy of renal pelvic dilatation in determining outcome of congenital hydronephrosis. Iran J Kidney 
Dis. 2014;8(1):26-30. [PubMed: 24413717]

3. Lee JH, Choi HS, Kim JK, Won HS, Kim KS, Moon DH, et al. Nonrefluxing neonatal hydronephrosis and the risk of urinary tract infection. J Urol. 2008;179(4):1524-8. doi: 10.1016/j.juro.2007.11.090. [PubMed: 18295269]

4. Molina CA, Facincani I, Muglia VF, Araujo WM, Cassini MF, Tucci Jr S. Postnatal evaluation of intrauterine hydronephrosis due to ureteropelvic junction obstruction. Acta Cir Bras. 2013;28 Suppl 1:33-6. [PubMed:23381821]

5. Ismaili K, Piepsz A. The antenatally detected pelvi-ureteric junction stenosis: advances in renography and strategy of management. Pediatr Radiol. 2013;43(4):428-35. doi: 10.1007/s00247-0122505-0. [PubMed: 23525768]

6. Ismaili K, Avni FE, Wissing KM, Hall M, Brussels Free University Perinatal Nephrology Study G. Long-term clinical outcome of infants with mild and moderate fetal pyelectasis: validation of neonatal ultrasound as a screening tool to detect significant nephrouropathies. J Pediatr. 2004;144(6):759-65. doi: 10.1016/j. jpeds.2004.02.035. [PubMed: 15192623]

7. Avni EF, Ayadi K, Rypens F, Hall M, Schulman CC. Can careful ultrasound examination of the urinary tract exclude vesicoureteric reflux in the neonate? Br J Radiol. 1997;70(838):977-82. doi: 10.1259/bjr.70.838.9404197. [PubMed: 9404197]

8. Pates JA, Dashe JS. Prenatal diagnosis and management of hydronephrosis. Early Hum Dev. 2006;82(1):3-8. doi: 10.1016/j.earlhumdev.2005.11.003. [PubMed:16380224]

9. Woodward M, Frank D. Postnatal management of antenatal hydronephrosis. BJU Int. 2002;89(2):149-56. [PubMed: 11849184]

10. Sinha A, Bagga A, Krishna A, Bajpai M, Srinivas M, Uppal R, et al. Revised guidelines on management of antenatal hydronephrosis. Indian Pediatr. 2013;50(2):215-31. [PubMed: 23474928]

11. Fernbach SK, Maizels M, Conway JJ. Ultrasound grading of hydronephrosis: introduction to the system used by the Society for Fetal Urology. Pediatr Radiol.1993;23(6):478-80. [PubMed: 8255658]

12. Estrada CR, Peters CA, Retik AB, Nguyen HT. Vesicoureteral reflux and urinary tract infection in children with a history of prenatal hydronephrosis--should voiding cystourethrography be performed in cases of postnatally persistent grade II hydronephrosis? J Urol. 2009;181(2):801-6. doi: 10.1016/j.juro.2008.10.057. [PubMed: 19095265]

13. Passerotti CC, Kalish LA, Chow J, Passerotti AM, Recabal P, Cendron $\mathrm{M}$, et al. The predictive value of the first postnatal ultrasound in children with antenatal hydronephrosis. J Pediatr Urol. 2011;7(2):128-36. doi: 10.1016/j.jpurol.2010.09.007. [PubMed: 20951094]

14. Coplen DE, Austin PF, Yan Y, Blanco VM, Dicke JM. The magnitude of fetal renal pelvic dilatation can identify obstructive postnatal hydronephrosis, and direct postnatal evaluation and management. J Urol. 2006;176(2):724-7. doi: 10.1016/j.juro.2006.03.079. [PubMed:16813930]

15. Alconcher LF, Tombesi MM. Natural history of bilateral mild isolated antenatal hydronephrosis conservatively managed. Pediatr Nephrol. 2012;27(7):1119-23. doi: 10.1007/s00467-012-2113-0. [PubMed: 22350369]

16. Toiviainen-Salo S, Garel L, Grignon A, Dubois J, Rypens F, Bois vert J, et al. Fetal hydronephrosis: is there hope for consensus? Pediatr Radiol. 2004;34(7):519-29. doi: 10.1007/s00247-004-1185-9. [PubMed: 15107962]

17. Tombesi MM, Alconcher LF. Short-term outcome of mild isolated antenatal hydronephrosis conservatively managed. I Pediatr Urol. 2012;8(2):129-33. doi: 10.1016/j.jpurol.2011.06.009. [PubMed: 21798811]

18. Vemulakonda V, Yiee J, Wilcox DT. Prenatal hydronephrosis: postnatal evaluation and management. Curr Urol Rep. 2014;15(8):430. doi:10.1007/s11934-014-0430-5. [PubMed: 24927968]

19. Ismaili K, Avni FE, Hall M, Brussels Free University Perinatal Nephrology Study G. Results of systematic voiding cystourethrography in infants with antenatally diagnosed renal pelvis dilation.J Pediatr. 2002;141(1):21-4. doi: 10.1067/mpd.2002.125493. [PubMed: 12091846]

20. Kari JA, Habiballah S, Alsaedi SA, Alsaggaf H, Al-dabbagh A, AbulHamail A, et al. Incidence and outcomes of antenatally detected congenital hydronephrosis. Ann Saudi Med.2013;33(3):260-4. doi: 10.5144/0256-4947.2013.260. [PubMed: 23793428]

21. Ismaili K, Hall M, Donner C, Thomas D, Vermeylen D, Avni FE, et al. Results of systematic screening for minor degrees of fetal renal pelvis dilatation in an unselected population. Am J Obstet Gynecol. 2003;188(1):242-6. [PubMed: 12548224]

22. Nguyen HT, Herndon CD, Cooper C, Gatti J, Kirsch A, Kokorowski P, et al. The Society for Fetal Urology consensus statement on the evaluation and management of antenatal hydronephrosis. J Pediatr Urol. 2010;6(3):212-31. doi: 10.1016/j.jpurol.2010.02.205. [PubMed: 20399145]

23. Holmes N, Harrison MR, Baskin LS. Fetal surgery for posterior urethral valves: long-term postnatal outcomes. Pediatrics. 2001;108(1):E7. [PubMed:11433086]

24. Phan V, Traubici J, Hershenfield B, Stephens D, Rosenblum ND, Geary DF. Vesicoureteral reflux in infants with isolated antenatal hydronephrosis. Pediatr Nephrol. 2003;18(12):1224-8. doi:10.1007| s00467-003-1287-x. [PubMed: 14586679]

25. Moon DH, Park YS, Jun NL, Lee SY, Kim KS, Kim JH, et al. Value of supranormal function and renogram patterns on 99mTc-mercaptoacetyltriglycine scintigraphy in relation to the extent of hydronephrosis for predicting ureteropelvic junction obstruction in the newborn.J Nucl Med.2003;44(5):725-31. [PubMed:12732673]

26. Oh SJ, Moon DH, Kang W, Park YS, Park T, Kim KS. Supranormal differential renal function is real but may be pathological: assessment by $99 \mathrm{~m}$ technetium mercaptoacetyltriglycine renal scan of congenital unilateral hydronephrosis. J Urol. 2001;165(6 Pt 2):2300-4. [PubMed: 11371941]

27. Amarante J, Anderson PJ, Gordon I. Impaired drainage on diuretic renography using half-time or pelvic excretion efficiency is not a sign of obstruction in children with a prenatal diagnosis of unilateral renal pelvic dilatation. J Urol. 2003;169(5):1828-31. doi: 10.1097/01.ju.0000062640.46274.21. [PubMed:12686855]

28. Yohannes P, Hanna M. Current trends in the management of posterior urethral valves in the pediatric population. Urology. 2002;60(6):947-53. [PubMed: 12475647]

29. Sarhan O, Zaccaria I, Macher MA, Muller F, Vuillard E, Delezoide $\mathrm{AL}$, et al. Long-term outcome of prenatally detected posterior urethral valves: single center study of 65 cases managed by primary valve ablation. J Urol. 2008;179(1):307-12. doi: 10.1016/j. juro.2007.08.160. [PubMed: 18006017]

30. Bajpai M, Dave S, Gupta DK. Factors affecting outcome in the management of posterior urethral valves. Pediatr Surg Int. 2001;17(1):11-5. doi: 10.1007/s003830000496. [PubMed: 11294258]

31. Hubertus J, Plieninger S, Martinovic V, Heinrich M, Schuster $\mathrm{T}$, Burst $\mathrm{M}$, et al. Children and adolescents with ureteropelvic junction obstruction: is an additional voiding cystourethrogram necessary? Results of a multicenter study. World J Urol. 2013;31(3):683-7. doi: 10.1007/s00345-012-0918-x. [PubMed: 22850807]

32. Liu DB, Armstrong W3, Maizels M. Hydronephrosis: prenatal and postnatal evaluation and management. Clin Perinatol. 2014;41(3):661-78. doi:10.1016/j.clp.2014.05.013. [PubMed: 25155734]

33. Sencan A, Carvas F, Hekimoglu IC, Caf N, Sencan A, Chow J, et al Urinary tract infection and vesicoureteral reflux in children with mild antenatal hydronephrosis. J Pediatr Urol. 2014;10(6):1008-13. doi:10.1016/j.jpurol.2014.04.001. [PubMed: 24863985]

34. Avni FE, Hall M, Cassart M. The postnatal workup of congenital uronephropathies. In: Fotter R, editor. Pediatric Uroradiology. Berlin: Springer; 2008. pp. 251-70.

35. Hong YK, Lee JH. Evaluation and Management of Antenatal Hydronephrosis. Childhood Kidney Dis. 2015;19(1):8-13. doi: 10.3339| chikd.2015.19.1.8.

36. Payabvash S, Kajbafzadeh AM, Saeedi P, Sadeghi Z, Elmi A, Mehdizadeh M. Application of magnetic resonance urography in diagnosis of congenital urogenital anomalies in children. Pediatr Surg Int. 2008;24(9):979-86. doi: 10.1007/s00383-008-2196-7. [PubMed:18668256]

37. Bassanese G, Travan L, D'Ottavio G, Monasta L, Ventura A, Pennesi M. Prenatal anteroposterior pelvic diameter cutoffs for postnatal referral for isolated pyelectasis and hydronephrosis: more 
is not always better. J Urol. 2013;190(5):1858-63. doi: 10.1016/j. juro.2013.05.038. [PubMed: 23707454]

38. Lee NG, Rushton HG, Peters CA, Groves DS, Pohl HG. Evaluation of prenatal hydronephrosis: novel criteria for predicting vesicoureteral reflux on ultrasonography. J Urol. 2014;192(3):914-8. doi: 10.1016/j.juro.2014.03.100. [PubMed:24704010]

39. Herndon CD, McKenna PH, Kolon TF, Gonzales ET, Baker LA, Docimo SG. A multicenter outcomes analysis of patients with neonatal reflux presenting with prenatal hydronephrosis. J Urol. 1999;162(3 Pt 2):1203-8. [PubMed:10458467]

40. Lee RS, Cendron M, Kinnamon DD, Nguyen HT. Antenatal hydronephrosis as a predictor of postnatal outcome: a meta-analysis. Pediatrics. 2006;118(2):586-93. doi: 10.1542/peds.2006-0120. [PubMed: 16882811]

41. Policiano C, Djokovic D, Carvalho R, Monteiro C, Melo MA, Graca
LM. Ultrasound antenatal detection of urinary tract anomalies in the last decade: outcome and prognosis. J Matern Fetal Neonatal Med. 2015;28(8):959-63. doi: 10.3109/14767058.2014.939065. [PubMed: 24975200]

42. Safai Asl A, Maleknejad S. Clinical outcome and follow-up of prenatal hydronephrosis. Saudi J Kidney Dis Transpl. 2012;23(3):52631. [PubMed: 22569439]

43. Anderson NG, Fischer J, Leighton D, Hector-Taylor J, McEwing RL. Management in children of mild postnatal renal dilatation but without vesicoureteral reflux. Pediatr Nephrol. 2010;25(3):477-83. doi:10.1007/s00467-009-1348-x. [PubMed:19921278]

44. Mudrik-Zohar H, Meizner I, Bar-Sever Z, Ben-Meir D, Davidovits M Prenatal sonographic predictors of postnatal pyeloplasty in fetuses with isolated hydronephrosis. Prenat Diagn. 2015;35(2):1427. doi:10.1002/pd.4505. [PubMed: 25266566] 